\title{
$\bullet \cdot$ \\ IJCRR \\ Section: Healthcare \\ Morphological Anatomy of Round Window for Electrode Insertion through Facial Recess Approach: A Soft Surgical Technique
}

ISI Impact Factor

(2019-20): 1.628

IC Value (2019): 90.81

$\operatorname{SJIF}(2020)=7.893$

(c) (i) (3)

Copyright@IJCRR

\author{
Kalambe $\mathbf{S}^{1}$, Jain $\mathbf{S}^{1}$, Gaurkar $\mathbf{S}^{1}$, Saini $\mathbf{A}^{1}$, Bhalerao $\mathbf{P}^{1}$, Chaudhary $\mathbf{G}^{2}$ \\ 'Assistant Professor, Department of Otorhinolaryngology, Datta Meghe Medical College, Nagpur, lndia; ${ }^{2}$ Computer Technology, Yeshwantrao \\ Chavan College of Engineering, Nagpur, India.
}

\section{ABSTRACT}

Background: Cochlear implantation is one of the most commonly used surgically techniques used in today's world for adults and children having sensorineural hearing loss. During cochlear implantation, there are surgical key steps that are influenced by the anatomical variation of each individual.

Objective: The aim was to study the anatomical characteristics of human RW and its importance for electrode insertion for the preservation of residual hearing in the process of cochlear implantation $(\mathrm{Cl})$ surgery.

Methods: Five human cadaveric temporal bones were obtained. Microdissection was done through facial recess approach and after dissection of the bone in the area of round and oval window (OW), height and width of the RW were noted, the distance between OW-RW was measured.

Results: The average height and width of the RW were $0.76+0.065 \mathrm{~mm}$ and $0.81+0.29 \mathrm{~mm}$, respectively. The distance between OW-RW was $2.52+0.53 \mathrm{~mm}$

Conclusions: Electrode insertion could be challenging in cases where the height and width of RW are $<1 \mathrm{~mm}$. This will help to select slimmer and less traumatic electrodes for cochlear implantation to avoid injury to neurovascular structures and preserve residual hearing.

Key Words: Round window, Cochleostomy, Facial recess, Cochlear implantation

\section{INTRODUCTION}

Cochlear implantation has become a common surgical procedure in adults and children with severe to profound hearing loss for restoration of speech. Initially, surgical eligibility was limited to individuals with total deafness because this procedure frequently destroyed any remaining residual hearing. The cochlear implant electrode insertion trauma was first published in $1985 .{ }^{1}$ Over time, surgical technique has been refined to minimize intracochlear trauma and to optimize placement of electrode contacts within the scala tympani with respect to spiral ganglion neurons. Since then atraumatic surgery has been of importance to the research and medical community as developments in cochlear implant (CI) models (e.g. midscale CIs) are increasingly focused on reducing intracochlear trauma. ${ }^{2}$

With the emergence of slimmer and less traumatic electrode designs and the emphasis on preservation of residual hearing by soft surgical technique round window, insertion technique has again become an area of interest for otorhinolaryngology surgeons in today's era of cochlear implantation.

The placement of a cochlear implant (CI) electrode into the scala tympani was first introduced using the round window technique. ${ }^{3}$ Since then, different approaches have been proposed to improve visualization, ease of electrode insertion and, more recently, for emphasis on preservation of residual hearing. Depending upon the surgeon's skills, when performing cochlear implantation, various options to insert the electrode into the scala tympani through the round window (RW), with or without drilling RW niche, or via a cochleostomy adjacent to the round window, based on anatomy and/ or surgeon preference.

The benefits of RW insertion are minimal acoustic trauma due to drilling of otic bone, which is seen in cochleostomy, minimizing loss of perilymph, entry of bone dust, blood and

\section{Corresponding Author:}

Dr. Sanika Kalambe Ghate, Assistant Professor, Department of Otorhinolaryngology and Head and Neck Surgery, Datta Meghe Medical College, Datta Meghe Institute of Medical Sciences, Wanadongri, Nagpur, Maharashtra, India; Phone: 9158973373; Email: sanika525@gmail.com

ISSN: 2231-2196 (Print)

Received: 25.09 .2020
ISSN: 0975-5241 (Online)

Revised: 16.11 .2020
Accepted: 06.01 .2021
Published: 04.06 .2021 
powder of gloves into scala tympani which cause reactive inflammation. Postoperative vertigo can be minimized by the RW insertion technique. Anatomical variations are documented in the literature. Hence the surgeon must be oriented with the variations of RW for correct placement of electrode and for the successful outcome of hearing in cochlear implantation patients. Incorrect placement of the electrode may cause device failure with loss of hearing restoration.

The present study was undertaken to study the surgical anatomy of the round window according to its morphology and its distance with the oval window and to make some guidelines for successful electrode insertion.

\section{MATERIALS AND METHODS}

An observational study was carried out in JNMC, DMIMS, Sawangi, India within six months of duration. Ten human wet, normal cadaveric temporal bones were selected for the study. Five bones were excluded because of traumatic damage of petrous temporal bone during anatomical preparation for cranial cavity contents. Diseased temporal bones and traumatic temporal bones were excluded. Thus, only five specimens were studied. This study was approved by the Research Ethics Committee.

Each temporal bone was mounted on the temporal bone holder and using standard auto surgical instruments, dissection was done on Carl Zeiss OPMI PICO microscope under magnification. The bones were dissected with a motor drill, starting from McEwan's triangle, after the periosteum over the mastoid bone was removed, and the mastoid cortex exposed. Then a complete mastoidectomy was performed. Posterior tympanotomy was then performed as it would be suitable for cochlear implant surgery and to measure the visibility of the round window membrane through the facial recess using an angle of view that gave the round window niche maximum visibility. The RW and OW areas on the medial wall of the tympanic cavity were revealed after the tympanic membrane and ear ossicles were removed. The RW and its relation to OW have been observed.

The dissected bones were photographed by a digital camera of 48 megapixels. The photographs were then imported to a computer to determine the following parameters using ScopyDoc 8.0.0.22 version software, after proper calibration and at $1 \mathrm{x}$ magnification (Figure 1).

1. RW height (RWh)

2. RW width (RWw)

3. Distance between RW-OW (from anterior margin of $\mathrm{RW}$ to the anterior margin of the oval window).

\section{Statistical analysis}

Statistical analysis of the data was done using MS Office 2007 Excel spreadsheet and program SPSS 20.0. Mean, standard deviation and correlation of different parameters were calculated using Pearson's correlation coefficient. A value of $p<0.05$ was taken as statistically significant.

\section{RESULTS}

\section{Size of RW}

The average height and width of RW measured were 0.76 $\pm 0.065 \mathrm{~mm}$ and $0.81 \pm 0.29 \mathrm{~mm}$, respectively. Table 1 showed there was a positive correlation between the height and the width of RW $(r=0.5675)$.

\section{Distance of RW-OW}

The distance between OW-RW was $2.52 \pm 0.53 \mathrm{~mm}$ (Table 1). The distance was in the range of $2-3 \mathrm{~mm}$ in all the bones (Table 1).

Table 1: Dimensions of RW and Distance of Round
Window from the oval window $(\mathbf{n}=\mathbf{0})$
\begin{tabular}{lcc} 
PARAMETERS & MEAN \& SD & RANGE \\
RWh & $0.76+0.065 \mathrm{~mm}$ & $0.7-1 \mathrm{~mm}$ \\
$\mathrm{RWW}$ & $0.81+0.29 \mathrm{~mm}$ & $0.6-1 \mathrm{~mm}$ \\
Distance of OW-RW & $2.52+0.53 \mathrm{~mm}$ & $2-3 \mathrm{~mm}$ \\
\hline
\end{tabular}

$\mathrm{n}$ - number of bones; SD, standard deviation. Maximum height of the round window (RWh), the maximum width of the round window $(\mathrm{RWw})$.

\section{DISCUSSION}

Cochlear implantation has become a treatment of choice for severe to profound hearing loss in adults and children unilaterally or bilaterally. Patient selection criteria have changed over the years. Initially, CI was done only for the restoration of hearing, but with the advances in CI electrode design, surgeons are focused on speech perception and soft surgeries.

The interest in using residual acoustic hearing has emerged recently. Using the still usable apical hair cells, the combined electrical and acoustic stimulation of the hearing-impaired cochlea perceives low-frequency sounds amplified by a hearing aid, whereas the high-frequency sounds are supplied electrically by a CI electrode. The human ear is capable of integrating speech information that is both auditory and electrically processed.

\section{SIZE OF RW}

We have summarize the size of round window reported in the number of previous studies (Table 2). The reason for these differences may be difficulties in assessing the reference points because of the RW distorted architecture. These dimensions have implications with round window insertion of 
electrodes as all the currently available electrode sizes will not be possible to be inserted through the smaller sized RW membranes.

In favourable round window anatomy, direct insertion through the RW is assumed to be the least traumatic approach. When the anatomy is less favourable/unfavourable and the patient has no residual hearing, the RW and the area of the hook can be enlarged, allowing good visualization of the scala tympani. Finally, when anatomy requires and residual hearing is present or by surgeon preference, a cochleostomy may be the method of choice as it involves less drilling and may also be advantageous with particular electrode designs. $^{9}$

\section{Table 2: Size of Round Window as Reported by Recent Studies}

\begin{tabular}{llclc} 
References & Study & No. of specimens & Parameter & Mean \pm SD Range $(\mathrm{mm})$ \\
\hline Erixon et al., (2009) $^{4}$ & Silicon casts & 65 & Half diameter of RW & $1.1\left(0.3^{-1.6)}\right.$ \\
Cohen et al., (2005) $^{5}$ & CT scans of patients & 414 & RW length & $1.665 \pm 0.258(1-2.70)$ \\
Su et al., (1982) & Histological & 541 & RWw & $1.66(0.48-2.7)$ \\
Singla et al, (2014) & Gross cadaveric & 50 & RWh & $1.62 \pm 0.77(0.8-3.77)$ \\
Singla et al, (2014) & Gross cadaveric & 50 & RWw & $1.15 \pm 0.39(0.64-2.15)$ \\
Jain et al $^{8}$ & Gross cadaveric & 34 & RWh & $0.69 \pm 0.25 \mathrm{~mm}$ \\
Jain et al $^{8}$ & Gross cadaveric & 34 & RWw & $1.16 \pm 0.47 \mathrm{~mm}$ \\
Our study & Gross cadaveric & 05 & RWh & $0.76+0.065 \mathrm{~mm}$ \\
Our study & Gross cadaveric & 05 & RWw & $0.81+0.29 \mathrm{~mm}$ \\
\hline
\end{tabular}

Intracochlear trauma due to a cochlear implant includes two kinds of lesions: immediate or initial lesions, which are represented by the trauma caused by the path of the electrode on the intracochlear structures, and delayed lesions, defined as new fibrous tissue or bone formed secondary to this initial trauma. ${ }^{10}$ Previous studies have shown great variations in the amount of fibrosis and new bone formation, ${ }^{10,11,12}$ but none have focused on the proximal cochlear lesions as a function of the surgical method of insertion.

To preserve the structure of the cochlea and potentially preserve residual low-frequency hearing in patients with residual functional hearing but not benefiting from hearing aids alone, the concept of both soft surgery and combined electric and acoustic (hybrid) stimulation was being intro- duced. ${ }^{13,14}$ This resulted in the development of smaller, shorter and more flexible lateral wall electrodes, such as the Flex series (MED-EL, Innsbruck Austria) and SlimJJ Straight electrodes (Cochlear Ltd., Sydney Australia), Hybrid-L24 and Slim Straight electrodes (Sydney Australia) (Advanced Bionics, Valencia USA). To allow round window insertion and shorter distances to reduce trauma and complete loss of residual low-frequency hearing, these lateral wall electrodes were designed with smaller diameters. ${ }^{15,16}$

\section{DISTANCE OF OW-RW}

OW has a direct superior relation with the RW. In our study, the RW was at an average distance of $22.52 \pm 0.53 \mathrm{~mm}$ (range 2-3 $\mathrm{mm}$ ) from the OW (Table 3).

\section{Table 3: Distance of OW-RW as Reported by Recent Studies}

\begin{tabular}{|c|c|c|c|c|}
\hline References & Parameter & Mean \& SD(range) & No. of bones & Study \\
\hline Seliet et al. ${ }^{17}$ & Min. dist. Between OW-RW & $2.09 \pm 0.69 \mathrm{~mm}($ range $1-3.5 \mathrm{~mm})$ & 20 & Cadaver \\
\hline Singla et al. $(2015)^{7}$ & Min. dist. Between OW-RW & $2.19 \pm 0.43($ range1.39-3.57) & 50 & Cadaver \\
\hline Paprocki et al. (2004) ${ }^{18}$ & Min. dist. Between OW-RW & $1.43 \pm 0.279 \mathrm{~mm}(1-1.75 \mathrm{~mm})$ & 10 & Cadaver \\
\hline Stewart \& Belal $(1981)^{19}$ & $\begin{array}{l}\text { Dist. from the superior margin of } \\
\text { RW niche to the inferior edge of } \\
\text { the OW }\end{array}$ & $2.7 \mathrm{~mm}$ (range 1.9-3.3) & 12 & Cadaver \\
\hline Dahm et al. (2009) $)^{20}$ & Mean dist. Between OW-RW & $4.1-4.5 \mathrm{~mm}+0.34 \mathrm{~mm}$ & 60 & Cadaver \\
\hline Jain et al. ${ }^{8}$ & Mean dist. Between OW-RW & $2.02+0.56 \mathrm{~mm}$ & 34 & Cadaver \\
\hline Our study & $\begin{array}{l}\text { Distance from anterior margin of } \\
\text { OW to anterior margin of RW }\end{array}$ & $22.52+0.53 \mathrm{~mm}($ range $2-3 \mathrm{~mm})$ & 05 & Cadaver \\
\hline
\end{tabular}

The frequent error is the implantation of the hypotympanic cell. Therefore, reliance on other landmarks (i.e. oval win- dow position) after opening facial recess is important. The RW-OW distance is also important in stapedectomy surgery 
to avoid the risk of injury to the RW membrane. Jain et. al conducted an anatomical study of the facial recess with implications in round window visibility for cochlear implantation. ${ }^{21}$ Few of the related studies were reported. ${ }^{22-26}$

\section{CONCLUSION}

Prior information of Round window- Oval window distance, RW anatomy and variation helps reduce complications during CI surgery, decrease surgery period and will always give successful hearing and speech restoration. HRCT Temporal bone may not always be helpful to study the anatomical variation and hence, knowledge of the above parameters and their relation to the surrounding neurovascular structures will be helpful for the surgeon while operating for cochlear implantation. This will help to modify the criteria of surgery, selection of pathway for electrode insertion (RW or cochleostomy) and the type of electrode depending upon the anatomy of RW for atraumatic insertion.

\section{Conflict of interest: Nil}

\section{Source of funding: Nil}

Ethical clearance: Taken from the institutional ethics committee

\section{REFERENCES}

1. Shepherd RK, Clark GM, Pyman BC, Webb RL. Banded intracochlear electrode array: evaluation of insertion trauma in human temporal bones. Ann Otol Rhinol Laryngol. 1985;94:55-59.

2. Jiam NT, Limb CJ. The impact of round window vs cochleostomy surgical approaches on interscalar excursions in the cochlea: Preliminary results from a flat-panel computed tomography study. World J Otorhinol Head Neck Surg. 2016;2(3):142.

3. House, WF. Surgical considerations in cochlear implantation. Cochlear implants: progress and perspectives. Ann Otol Rhinol Laryngol. 1982;91:15-20.

4. Erixon E, Hogstrop H, Wadin K, Rask-Andersen H. Variational anatomy of the human cochlea: implication for cochlear implantation. Otol Neurotol 2009;30:14-22.

5. Cohen D, Blinder G, Perez R, Raveh D. Standardized computed tomographic imaging and dimensions of the round window niche. Int Tinnitus J. 2005;11:158-62.

6. Su WY, Marion MS, Hinojosa R, Matz GJ. Anatomical measurements of the cochlear aqueduct, round window membrane, round window niche, and facial recess. Laryngology. 1982;92:483-6.

7. Singla A, Sahni D, Gupta AK, Loukas M, Aggarwal A. Surgical anatomy of round window and its implications for cochlear implantation. Clin Anat. 2014; 27(3):331-6.

8. Jain S, Gaurkar S, Deshmukh PT, Khatri M, Kalambe S, Lakhotia $\mathrm{P}$, et al. Applied anatomy of round window and adjacent structures of tympanum related to cochlear implantation. Braz $\mathrm{J}$ Otorhinolar. 2019;85(4):435-446.

9. Richard C, Fayad JN, Doherty J, Linthicum FH. Round window versus cochleostomy techniques in cochlear implantation: histological findings. Otol Neurotol. 2012;33:1181e1187.
10. Li PM, Somdas MA, Eddington DK. Analysis of intracochlear new bone and fibrous tissue formation in human subjects with cochlear implants. Ann Otol Rhinol Laryngol. 2007;116:731738.

11. Nadol JB Jr, Shiao JY, Burgess BJ, et al. Histopathology of cochlear implants in humans. Ann Otol Rhinol Laryngol. 2001;110:883-891.

12. Fayad J, Linthicum FH Jr. Otto SR, Galey FR, House WF. Cochlear implants: histopathologic findings related to performance in 16 human temporal bones. Ann Otol Rhinol Laryngol. 1991;100:807-811.

13. Lehnhardt E. Intracochlear placement of cochlear implant electrodes in soft surgery technique. Ann Otol Rhinol Laryngol. 1993;41:356-9.

14. Gantz BJ, Turner CW. Combining acoustic and electrical hearing. Laryngos 2003;113: 1726-30.

15. Lenarz T, Stöver T, Buechner A, Lesinski-Schiedat A, Patrick J, Pesch J. Hearing conservation surgery using the Hybrid-L electrode. Results from the first clinical trial at the Medical University of Hannover. Audiol Neurotol 2009;14(1):22-31.

16. Skarzynski H, Lorens A, Matusiak M, Porowski M, Skarzynski PH, James CJ. Cochlear implantation with the nucleus slim straight electrode in subjects with residual low-frequency hearing. Ear Hear. 2014;35:e33-43.

17. Seliet AM, El Hamshary AS, Refai AM, Ali AM, Gabal SR. Human round window: morphometry and topographical anatomy and their effect on cochlear implantation. Benha Med J. 2018;35:246

18. Paprocki A, Biskup B, Kozłowska K, Kuniszyk A, Bien D, Niemczyk K. The topographical anatomy of the round window and related structures for the purpose of cochlear implant surgery. Folia Morphol (Warsz). 2004;63(3):309-312.

19. Stewart TJ, Belal A. Surgical anatomy and pathology of the round window. Clin Otol Allied Sci. 1981;6(1):45-62.

20. Dahm MC, Shepherd RK, Clark GM. The Postnatal Growth of the Temporal Bone and its Implications for Cochlear Implantation in Children. Acta Otolaryngol. 2009;113(3):4-39. doi: $10.3109 / 00016489309128539$.

21. Jain S, Deshmukh P. Lakhotia S. Kalambe D. Chandravanshi A, Khatri M. Anatomical Study of the Facial Recess with Implications in Round Window Visibility for Cochlear Implantation: Personal Observations and Review of the Literature. Int Arch Otorhinol. 2019; 23(3): E281-91.

22. James SL, Castle CD, Dingels ZV, Fox JT, Hamilton EB, Liu Z, et al. Estimating global injuries morbidity and mortality: Methods and data used in the Global Burden of Disease 2017 study. Injury Prev. 2020;26(1):I125-I153.

23. James SL, Castle CD, Dingels ZV, Fox JT, Hamilton EB, Liu Z, et al. Global injury morbidity and mortality from 1990 to 2017 : Results from the global burden of disease study 2017. Injury Prev. 2020;26(1):96-114

24. Fulzele P, Quazi Z, Sirsam A, Khobargade S, Chitriv Y, Singh $\mathrm{K}$, et al. Methods for early detection of postoperative infection- a review. J Adv Res Dyn Control Syst 2019;11(8 Special Issue):3155-3167.

25. Jain S, Jungade A. Ranjan P. Singh A. Panicker C. Singh P. Revisiting 'Meniere's Disease' as 'Cervicogenic Endolymphatic Hydrops' and Other Vestibular and Cervicogenic Vertigo as 'Spectrum of Same Disease': A Novel Concept. Ind J Otolary Head Neck Surg. 2020;12(5):46-49.

26. Methwani DA, Deshmukh PT. Comparative Study of Type I Tympanoplasty with or without Mastoidectomy in Tubotympanic Type of Chronic Suppurative Otitis Media Patients. J Datta Meghe Inst Med Sci Univ. 2017;12(2):85-88. 